\title{
SOBRE FORMAR LEITORES E ESCRITORES EQUILIBRISTAS: DAS POSSIBILIDADES DO ESPAÇO-ESCOLA
}

\author{
ABOUT TO EDUCATE EQUILIBRIST READERS AND WRITERS: OF THE \\ POSSIBILITIES OF SCHOOL SPACE
}

\section{SOBRE LA FORMACIÓN DE LECTORES Y ESCRITORES EQUILIBRADORES: SOBRE LAS POSIBILIDADES DEL ESPACIO ESCOLAR}

Lara Jatkoske Lazo ${ }^{1}$

Eliane Aparecida Bacocina ${ }^{2}$

Resumo: Este artigo traz observações da experiência de docência e pesquisa com leitura e escrita. Objetiva apresentar relatos de práticas de leitura, pela pesquisa narrativa/autobiográfica. Conclui-se: a leitura é um ato integralizador da percepção estética.

Palavras-chave: Literatura clássica e popular; saraus; formação e escola.

\begin{abstract}
This article present observations of teaching and research experience with reading and writing. The objective is to present reports of reading practices, through narrative/autobiographical research. It concludes: reading is an act that integrates the aesthetic perception.
\end{abstract}

Keywords: Classic and popular literature; soirees; formation and school.

Resumen: Este artículo trae observaciones de la experiencia docente e investigadora con la lectura y la escritura. Tiene como objetivo presentar informes de prácticas lectoras, a través de investigaciones narrativas / autobiográficas. Concluye: la lectura es un acto que integran la percepción estética.

Palabras clave: Literatura clásica y popular; veladas; formación y escuela.

\section{Introdução}

Vou seguindo como Drummond,

Sem medo de tropeçar na pedra,

Vencendo do mundo a Quimera.

Com Augusto alinhavando ao compasso

Tudo o que faço,

Com a necessidade de ser fera, a ideia.

Tenho Vitor Hugo como plateia.

Miserável é sim, o insulto,

Que o cérebro inculto,

Nos leva nesta Dantesca Odisseia,

Que nada tem de Divina e muito de Comédia.

Quem sabe onde a rima se esconde,

Vai beber direto na fonte

E não se perde na métrica.

Essa sim seria a maior tragédia.

Minha musa não mora em Pasárgada,

\footnotetext{
${ }^{1}$ Universidade Estadual Paulista (Unesp) - Câmpus de Rio Claro.

${ }^{2}$ Instituto Federal de Educação, Ciência e Tecnologia de São Paulo (IFSP) - Câmpus Salto.
} 
Muito menos descansa em mornas águas.

E se nossas palmeiras

Não se assemelham com as de lá,

Convoco Castro Alves e Gonçalves

A cantarem a beleza deste lugar.

Que fique aos puristas o trabalho

De buscar no vernáculo

Destes paupérrimos vocábulos,

Que de horror se mostram em espetáculo,

$O$ sentido, que, em si, não é nulo.

De Lusíadas a Bilac num só pulo.

Como disse Caieiro em Pessoa

Mais vale o que não se pensa,

Pois quem diz que pensa ofaz à toa

Eu busco conquistar a recompensa

Transpondo da ignorância o muro

E a cada sentença, com inovação,

Inspiração nos clássicos sempre procuro.

Fernandes Oliveira, 2011, p. 46

\section{No balanço da leitura e da escrita, como puder, equilibre-se!}

Este artigo apresenta, pela pesquisa narrativa (LIMA; GERALDI; GERALDI, 2015) e autobiográfica (ARFUCH, 2002), reflexões da experiência prática de sala de aula e de pesquisa acadêmica a partir de ações docentes que visam à formação de leitores e escritores em uma escola integral agrícola de ensino fundamental e a partir das experiências de um poeta, que assim se constituiu, a partir de aulas de português.

Apresentam-se, como disparadores deste artigo: reflexões a partir do poeta Fernandes Oliveira do litoral sul paulista, que iniciou o hábito de escrita de poemas a partir de suas experiências em aulas de Língua Portuguesa no Ensino Fundamental II e Ensino Médio, e que traçou um percurso literário que se iniciou na escola e se projetou a toda sua vida; alguns elementos importantes na formação do leitor, na escola, em práticas de leitura, principalmente, coletivas, que envolveram a experiência em grupo como elemento a proporcionar um espaço de vivência pela leitura, de modo particular a cada sujeito.

Nas experiências relatadas, foram realizadas leituras de textos clássicos e modernos, por meio de metodologias dialógicas, dentre as quais se destacam os saraus e a leitura coletiva de clássicos literários, pois a linguagem ultrapassa os sentidos de ilhas sociais e culturais, ao conectar o que há de humano entre os sujeitos, sem a exclusão de suas particularidades culturais, pessoais e estéticas, pelas quais possibilita a eclosão dos estilos. Do poeta, a sua própria vida é um relato vivo, materializado em poesia, da influência e possibilidades oferecidas pela escola. Sua trajetória revela a força das práticas de leitura no ambiente escolar, enquanto formação do sujeito.

Um motivo da escolha dos saraus, para o trabalho com leitura na escola, é a possibilidade de expressão multilíngue, característica brasileira (GUIMARÃES, 2005, p. 22), ao permitir que os alunos, além de escolher as leituras que desejam (populares, regionais ou clássicas), também possam compor seus textos na linguagem que os agrada, ou que lhes é espontânea, como a linguagem coloquial, o que afasta a prática de leitura do "conceito de ideologia monolíngue" (PUH, 2020, p. 416), cuja proposta universalista acaba por invisibilizar as diferenças a favor do ensino de uma língua portuguesa única, que é colocada como superior: a língua do colonizador. 
O sarau, se democrático, pode possibilitar, portanto, um trabalho livre à criatividade e à exposição multicultural, sem praticar a invisibilidade das diferenças culturais, comum ao discurso universalista existente no Brasil (PUH, 2020, p. 416), que promove o apagamento das diferenças étnico-sociais já pelo uso do prefixo multi-, que unifica as diferenças e reforça "as políticas monolíticas" (PUH, 2020, p. 416). Os saraus democráticos caracterizam-se pela escolha livre dos textos, mesmo em um limite de possibilidades oferecido, por exemplo, por uma pequena biblioteca; também possibilita aos alunos que criem seus textos ou outros tipos de apresentação cultural, sem a promoção de um eixo linguístico e cultural específico. Em todos os tipos de leitura, como na leitura de clássicos literários, a criatividade pessoal é possível pela "atividade original" (PROUST, 2003, p. 39), que pode ser desenvolvida a partir de uma metodologia dialogada e de incentivo e liberdade à reflexão e crítica, com a articulação e diálogo da ficção com a realidade, pela palavra viva (BAKHTIN, 2011), e com outros textos lidos e discursos ouvidos. Da sala de aula ao poeta Fernandes, que declama e publica livros, há uma estética de criação e constituição da formação e individualidade (BAKHTIN, 2011) do leitor que não se limita ao gênero fixo (BAKHTIN, 2016) dos textos, mas à vivência com eles em cada realidade.

Nos contextos aqui apresentados, a prática de leitura partiu do exemplo, da prática social coletiva com alunos dos anos finais do Ensino Fundamental II. A metodologia de sala de aula se delineou pela livre expressividade e pelo diálogo a partir das leituras, ao criar um espaço afetivo (NOVASKI, 1988) e expressivo de conhecimento, que possibilita à leitura se impregnar de um ambiente positivo, com força de tocar a memória:

[...] o que as leituras da infância deixam em nós é a imagem dos lugares e dos dias em que as fizemos. Não escapei ao seu sortilégio: querendo falar delas, falei de outras coisas diferentes de livros, porque não é deles que elas me falaram. Mas talvez as lembranças que elas me trouxeram tenham elas mesmas sido despertadas nos leitores, conduzindo-os pouco a pouco - retardando-se nesses caminhos doridos e enviesados - a recriar em seu espírito o ato psicológico original chamado Leitura [...] (PROUST, 2003, p. 24-25).

O "ato psicológico original", cujo termo psicológico, por se tratar aqui de um viés bakhtiniano, pode ser substituído pela expressão ato dialógico original, em que o perceber e o sentir compõem um todo estético do ambiente, "misturado" à estética da leitura. $\mathrm{O}$ equilíbrio entre os elementos que constituem a leitura, como os ambientes físico, emocional, ficcional e sonoro, marca, ao mesmo tempo, o não-equilíbrio inicial que se processa entre eles, cujo efeito é, primeiro, balançar o leitor, tocá-lo, e, então, encontrar um equilíbrio, uma sintonia, ou não, da leitura com o real.

A literatura clássica é uma escolha na prática de leitura, pela sua complexidade linguística; pelo trabalho simbólico; sua genealogia dos gêneros, seu potencial de aproximar os adolescentes do adulto (o professor), para superar as dificuldades do texto; pelo seu trabalho estético; e pelo seu caráter sempre atual: "É clássico aquilo que persiste como rumor mesmo onde predomina a atualidade mais incompatível" (CALVINO, 2007, p. 15). A sua leitura pode ser realocada no novo contexto presente, como palavra viva (BAKHTIN, 2011).

Uma aluna definiu o termo clássico como: "Clássico é poder apreciar o sentido das escrituras, o motivo e a compaixão de saber o que é viver e aprender" (LAZO, 2018, p. 75). Sua percepção de clássico está atrelada ao se colocar na vida e no lugar do outro. O termo "compaixão" pode ter sido um equívoco no emprego de vocabulário, mas, também, pode ter sido a materialidade do sentir a partir do outro, do afeto que o outro, representação dos sujeitos do mundo, devolve-lhe: ela refrata a sua posição dialógica e realoca a ideia de clássico, como algo "antigo", mencionada por alunos da turma, no enunciado presente da experiência de vida. 


\section{Sobre o poeta Fernandes e suas incursões pela literatura}

O primeiro contato com Fernandes foi em 2011, numa roda literária no município de Praia Grande/SP, da qual a segunda autora deste artigo participou, com os estudantes da turma de Pedagogia com a qual trabalhava.

Poeta dinâmico. Principal divulgador do grupo do qual faz parte e de eventos nas redes sociais.

Nascido na Praia Grande há 35 anos, Fernandes conta, em entrevista, que fez parte do material de pesquisa do Doutorado da segunda autora (BACOCINA, 2017), que começou a escrever poesia por influência da escola, entre a $7^{\mathrm{a}}$ e $8^{\mathrm{a}}$ série, quando foi premiado por alguns poemas que escreveu:

Fernandes: Foi na $7^{\mathrm{a}}$ série... $7^{\mathrm{a}}$ pra $8^{\mathrm{a}} \ldots 8^{\mathrm{a}}$ série, eu tinha 14 anos e aí tinha, foi em 93. 'Vamos passear no parque, ho, deixa o menino brincar'.

Aí eu ouvia isso no rádio e eu ainda não sabia o que era.

E aí eu fiz uma paródia:

'Vamos todo mundo pra escola ho. Fim de semana jogar bola'.

Eu ainda não sabia o que era aquilo que estava tocando no rádio. Aí eu fiz uma paródia na escola e acabou que era pra fazer uma poesia e eu não consegui fazer até o final e acabou assim:

'não dá pra chegar no final porque está tocando o sinal'

e ganhei prêmio com isso na escola. E aí eu falei: 'cara, esse negócio de fazer poesia é legal!' Aí depois veio ‘droga é uma droga' que ficou uma droga, mas ficou legal também... na época, 14 anos. Aí eu falei: Cara! Dá pra você expor as suas ideias em forma de poesia. Foi aí quando eu comecei a descobrir. Uma era uma paródia e a outra era que droga é uma droga. Foram duas poesias que deram um supetão assim pra mim (BACOCINA, 2017, p. 30) ${ }^{3}$.

Observa-se como o poeta Fernandes retoma e realoca as leituras de clássicos em suas palavras:

Seguia Fernandes no caminho

E Drummond lia

No caminho lia Fernandes

Drummond e seguia

Drummond Fernandes lia

E no caminho seguia

Nunca esquecerei este dia

Em que no caminho que nada havia

Fernandes seguia

E nada via

E Drummond lia

De repente uma pedra (OLIVEIRA, 2011, p. 43).

Fernandes também conta que, durante os estudos no Ensino Médio, recebeu diversas influências de autores que lia durante as aulas e, a partir deles, foi aprofundando seus conhecimentos literários e seu interesse em escrever poemas.

E influências vieram depois, que com o Ensino Médio a gente começa a estudar os autores da própria literatura portuguesa e a brasileira e a gente vai

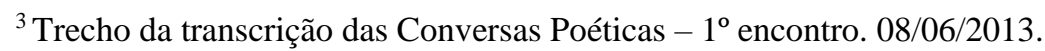


pra Camões, passa um pouco em Gregório de Matos, vou passear um pouco em Gil Vicente, dou uma passeadinha de leve no cara dos 100 sonetos, o Bocage. E Bocage já não soa nos poemas que eu mais gosto, porque ele nega tudo aquilo que afirma o que ele é, é um soneto. E foi quando eu me prendi aos sonetos era... fiz quase 100 sonetos em um ano, era quase um soneto a cada 3 dias, foi quando eu fui participar da Casa do Poeta pela primeira vez e mostrei um soneto que eu havia feito. Eu tava preso porque que tava lendo muito os antigos, clássicos. Essa linha antiga. Depois veio o Modernismo, algumas inspirações. Quando eu conheci... tive o meu encontro com Drummond e com Fernando Pessoa, foram duas paixões, e aí eu esmiucei nos próximos dois anos lendo tudo sobre eles. E com o advento da internet foi quando eu pude buscar e caí de cabeça neles. Drummond e Fernando Pessoa, foram os dois ícones. Aí tem um pouco de Augusto dos Anjos, mas esses dois assim são mais presentes (BACOCINA, 2017, p. 30) . $^{4}$

Este relato nos mostra como o ensino de Literatura Brasileira e Portuguesa no Ensino Médio e o contato com os clássicos estimularam a formação desse poeta, que chegou a escrever quase 100 sonetos em um ano, a partir do contato com o Modernismo e algumas inspirações. Quando Fernandes fala sobre seu encontro com Drummond e com Fernando Pessoa, fica evidente que não se trata de leituras obrigatórias que foram realizadas, pois nos remete a um encontro com amigos e mestres que exerceram forte influência sobre o estilo e a forma de escrita que ele desenvolveu.

É importante dizer que Fernandes, atualmente, possui livros de poemas publicados, além de ser um organizador de eventos poéticos relacionados à literatura periférica, no local onde habita, e contribui, com seu trabalho educativo e de divulgação, para que mais pessoas tenham acesso à cultura e à literatura. $\mathrm{O}$ menino que lia Drummond e se sentia motivado para seguir a pedra, hoje se tornou um incentivador, para que mais pessoas possam ter acesso à literatura e aos atos, estéticos e políticos, de ler e escrever as palavras e o mundo.

\section{Literatura clássica, saraus e vida escolar}

Serão relatadas, pela primeira autora (LAZO, 2018) deste artigo, algumas observações de experiências com a leitura coletiva de clássicos literários no Ensino Fundamental II em uma escola municipal agrícola, onde começou a trabalhar em 2010. Os relatos vão até os meses iniciais de 2020, antes do fechamento das escolas, devido à pandemia da Covid-19, pois, após isso, apenas foi possível enviar aos alunos textos impressos para leitura ou mensagens de voz, via WhatsApp, sem acompanhamento remoto e, portanto, sem diálogo antes, durante e após as leituras. As práticas de leitura relatadas se deram com turmas do $7^{\circ}$ aos $9^{\circ}$ anos, com adolescentes entre 12 e 16 anos. Após 2018, havia alunos com 17 anos. As leituras coletivas foram realizadas, algumas, em momentos de saraus (o que envolveu, algumas vezes, integrantes do PIBID ${ }^{5}$ ), e, a maioria, em momento de leitura oral coletiva, em que um lia, os outros ouviam, e todos dialogavam. Nos saraus não eram lidos apenas clássicos e, preferencialmente, liam-se poemas e não contos e romances.

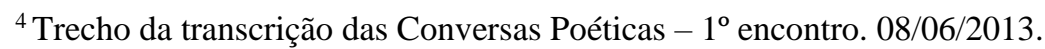

${ }^{5}$ Programa Institucional de Bolsas de Iniciação à Docência. "A Fundação Coordenação de Aperfeiçoamento de Pessoal de Nível Superior (Capes), no cumprimento das atribuições conferidas pelo Decreto no 7.692, de 02 de março de 2012, torna público que receberá de Instituições de Ensino Superior (IES), públicas e privadas sem fins lucrativos, propostas de projetos de iniciação à docência no âmbito do Programa Pibid Diversidade. Disponível em: http://www.capes.gov.br/legislacao/53-conteudo-estatico/servicos/2334-decretos. Acesso em: 18 jul. 2018.
} 
Experimentou-se a leitura de um romance clássico da literatura, "Os Miseráveis" Victor Hugo, sem adaptação e na versão integral, o que constituiu um espaço de leitura em que o adolescente se aproximou do adulto, no caso, a professora, para dar conta de uma linguagem não comum a ele. Essa aproximação, com liberdade de diálogo e expressão, que se dava por incentivo da professora, para que o diálogo se estabelecesse e se mantivesse, foi realizada de forma acolhedora da palavra do outro, com a busca de um ambiente agradável, familiar e com potencial de marcar a memória de forma positiva enquanto parte da leitura do texto.

Buscou-se superar as dificuldades da linguagem de forma dialogada e com pesquisas, em que todos participavam, o que tornava a construção da leitura um momento divertido, ativo, de constituição do conhecimento: "Outra coisa muito prazerosa que encontramos num bom livro é o prazer de decifração, de exploração daquilo que é tão novo que parece difícil e por isso mesmo, oferece obstáculos e atrai com intensidade" (MACHADO, 2002, p. 21). O estilo que se percebia, principalmente, nos alunos mais participativos, começava pela sua atenção nos temas do texto. A obra de Victor Hugo é extensa e politemática; de uma página era possível extrair diversos temas, o que fez com que cada aluno que se manifestasse fosse tocado por um ou outro tema. Desses alunos, durante a leitura e o diálogo dela, por exemplo, uma adolescente focou o tema da opção da vida eclesiástica por um jovem bonito e viril, a partir da história de um dos personagens, o Bispo Myriel: "Que desperdício, professora! Um rapaz bonito e rico...” (LAZO, 2018, p. 86). Tratou-se de uma manifestação oral que se referia à opção do personagem pela vida religiosa. $\mathrm{O}$ fato de a aluna ter mantido o foco no mesmo tema, durante as páginas seguintes, marcou um traço de seu modo de ler e de ser tocada. Outra aluna, por exemplo, mantinha-se focada nos conflitos, sendo o tema tristeza comum em seus discursos escritos: "Os Miseráveis me passou uma sensação boa e também revelou uma parte das tristezas da vida" (LAZO, 2018, p. 121).

Foi realizada a leitura até a página oitenta e três, ao término do ano de 2017. A leitura não tinha pressa; não era uma proposta avaliativa e obrigatória; era um momento de descontração e diálogo. Como professora, a educadora também precisou lidar com frustrações, já que, às vezes, a prática não rendia como esperado; outras, sim. Foi necessário se colocar no lugar do aluno e compreender a dinâmica das práticas. Após o almoço, por exemplo, os adolescentes se dispersavam mais; alguns dormiam no gramado, quando as práticas eram realizadas no jardim ou no campo. Observou-se que a leitura rendia mais de manhã e em espaços fechados, como relatou, por escrito, uma aluna, ao referirse a leituras nas áreas externas e gramadas da escola: "Estou gostando mais ou menos, porque não acho legal onde as aulas de leitura estão se realizando, acho que o ambiente não é bom, é mais por causa do calor, que tira muito a atenção dos alunos" (LAZO, 2018, p. 164). Na sala de aula, mesmo sendo um ambiente fechado, a temperatura quente era controlada por ventiladores.

Havia aulas em que o diálogo era constante; outras, em que não. O "espaço" da voz se revelou mais importante do que o espaço físico, porque, sem um bom tom de voz, expressividade ao ler, olho no olho, gesticulações e disparo de diálogos, a leitura não acontecia de forma efetiva, independentemente do ambiente físico em que era realizada. Por isso, deu-se predileção à professora na leitura do texto para a turma. Quando algum aluno lia, a turma se dispersava e os diálogos não eram estabelecidos. Nos saraus, os alunos se dispersavam por conta do "espaço" da voz, ainda pouco expressivo, durante as leituras realizadas por outros alunos, e por conta de terem se tornado uma atividade costumeira, o que dava a impressão de algo banal. Ao perceber isso, busquei programar os saraus não semanalmente e no mesmo dia da semana, mas espaçada e aleatoriamente.

\footnotetext{
${ }^{6}$ A minha leitura particular de "Os Miseráveis" foi da tradução mais antiga da obra integral da Edição das Américas de 1956-1957; a leitura que realizei com os meus alunos foi da tradução que eu tinha disponível na época, que é a da edição da Martin Claret: HUGO, V. O Miseráveis. Tradução e notas de Regina Célia De Oliveira. São Paulo: Martin Claret, 2015.
} 
Os saraus davam força ao hábito de leitura e à participação artística e social de ler, mas não eram aproveitados, pelos participantes, tal como objetivei, como momento de mais reflexões e diálogos. Os adolescentes focavam na participação em nível de 'estar ali', chamar a atenção, mas não prestavam a atenção no colega que lia e nem no sentido dos textos; ninguém perguntava ou discutia algo lido; quando os questionava, não sabiam dizer nada do que haviam ouvido, porque não prestaram a atenção. (LAZO, p. 164, 2018).

Desatrelar a ideia de rotina da prática dos saraus foi a forma positiva que foi encontrada para tornar efetivar a leitura, o que se deu não nos níveis de reflexão e diálogo, como se tencionava, mas de experimentação e conhecimento da linguagem, o que envolveu a expressão artística, a socialização, a aceitação e valorização das diferenças linguísticas e culturais; envolveu práticas de escrita de poesias, com trabalhos rítmicos e de rima; a valorização da cultura popular; e o desenvolvimento de um contato mais intenso e frequente com a leitura e a escrita.

Ler tanto obras clássicas como populares e da própria autoria dos alunos possibilitou um trabalho mais equilibrado entre estilo, expressividade, espontaneidade, reflexão e lógica. Os clássicos, além dos elementos estéticos que possibilitam à sensibilidade viagens sensíveis e intensas, exigem um trabalho intenso mental, lento, lógico e articulador dos elementos linguísticos, temporais, sociais, culturais, históricos e narrativos; nos textos populares, o enredo se destaca sobre outros elementos da arte e os elementos simbólicos e históricos, o que possibilita uma leitura fluente, sem que o adolescente necessite de um adulto para concluí-la com sucesso. Com estilos variados de texto, portanto, obteve-se um equilíbrio entre a autonomia e a necessidade de ouvir as pessoas mais experientes na vida (o adulto); entre a fluência e a dificuldade; entre modos diferentes de ler e se comportar na leitura; entre a forma de lidar com a temporalidade; entre a visibilidade mental (força das imagens na mente) e a sensação da arte.

\section{Considerações finais}

A leitura é leitura, individual ou coletivamente, não, apenas, enquanto palavras e imagens, mas enquanto uma estética (BAKHTIN, 2011) que extrapola os limites do texto escrito, oralizado ou imagético, mas que o integra e lhe dá vida. Envolve elementos sutis, como a memória, o ambiente físico, a postura, o modo de ler, o ritmo, o tom de voz, as entonações, os gestos, o silêncio; quem lê; o público ao redor; o porquê de determinado ato de leitura; os sentimentos e emoções individuais e do grupo; a cultura, as experiências pessoais, enfim, elementos esses e outros que constituem a leitura como um ato integralizador da percepção dos cinco sentidos às imagens narrativas e ao todo da leitura e vice-versa, em níveis de consciência e inconsciência, enquanto um todo absorvido pelos sentidos, em um momento de "atividade original" (PROUST, 2003, p. 39).

Nas experiências aqui apresentadas, as práticas educativas a partir da poesia são um contexto de "corpo" inteiro, sem limites definidos, o que torna a experiência uma constituição de vida e de possibilidades que ultrapassa, em muito, a prática de leitura e escrita como conteúdo de Língua Portuguesa, com foco na sintaxe, na interpretação de texto e nos gêneros discursivos. Pode-se afirmar que, mais que conhecimentos linguísticos e discursivos, estão presentes experiências afetivas com o texto, o que torna tais propostas ricas, marcantes e significativas na formação de leitores e escritores. Por isso, experiências equilibristas e com possibilidades singulares e infinitas. 


\section{Referências}

ARFUCH, Leonor. El espacio biografico: dilemas de la subjetividad contemporánea. Buenos Aires: Fundo de Cultura Económica de Argentina, S. A., 2002.

BACOCINA, Eliane Aparecida. Ler, escrever e compartilhar poesia: práticas (DES) territorializadas, políticas, coletivas. 2017. 210f. Tese (Doutorado em Educação) Universidade Estadual Paulista-UNESP, Rio Claro, 2017.

BAKHTIN, Mikhail. Estética da criação verbal. Trad. P. Bezerra. 6. ed. São Paulo: WMF/Martins Fontes, 2011.

BAKHTIN, Mikhail. Os gêneros do discurso. Trad. P. Bezerra. São Paulo: Editora 34, 2016.

CALVINO, Italo. Por que ler os clássicos. Trad. N. Moulin. São Paulo: Companhia de Bolso, 2007.

GUIMARÃES, Eduardo. Línguas do Brasil. Ciência e Cultura (Temas e Tendência), São Paulo, v. 57, n. 2, p. 22-25, abr./jun., 2005.

LAZO, Lara Jatkoske. Literatura clássica e práticas artísticas: narrativas e estudos de uma professora acerca da formação do leitor adolescente. 2018. 238f. Dissertação (Mestrado em Educação) - Instituto de Biologia, Universidade Estadual Paulista, Rio Claro, 2018.

LIMA, Maria Emília Caixeta de Castro; GERALDI, Corinta Maria Grisolia; GERALDI, João Wanderley. O trabalho com narrativas na investigação em educação. Educação em Revista, Belo Horizonte, v. 31, n. 01, p. 17-44, jan./mar. 2015. Disponível em: http://dx.doi.org/10.1590/01024698130280. Acesso em: 21 abr. 2018.

MACHADO, Ana Maria. Como e por que ler os clássicos universais desde cedo. Rio de Janeiro: Objetiva, 2002.

NOVASKI, Augusto. Mito e racionalidade filosófica. In: MORAIS, R. (Org.). As razões do mito. Campinas: Papirus, 1988. p. 25-30.

OLIVEIRA, Fernandes. Minhas pegadas na areia. Praia Grande: Literata, 2011.

PROUST, Marcel. Sobre a leitura. 4. ed. Trad. C. Vogt. Campinas: Pontes, 2003.

PUH, Milan. Tudo junto e misturado?: as contribuições e os limites do multiculturalismo no ensino de línguas. El toldo de Astier, año 11, n. 20-21, p. 415-432, jul. 2020. ISSN 1853-3124. Disponível em: http://www.eltoldodeastier.fahce.unlp.edu.ar/numeros/ numero20/pdf/Puh.pdf. Acesso em: 10 set. 2020.

\section{Sobre as autoras}

Lara Jatkoske Lazo. Doutoranda em Educação, na Linha de Linguagem - Experiência - Memória - Formação, pela Unesp, câmpus de Rio Claro - SP. Professora de Língua Portuguesa no Ensino 
Fundamental II, na E. M. A. "Eng. Rubens Foot Guimarães", de ensino integral, em Rio Claro. Diretora e professora de dança da academia Centro Intercultural Napyév, em Rio Claro.

E-mail: larajlazo@yahoo.com.

Eliane Aparecida Bacocina: Doutora em Educação pelo Programa de Pós Graduação em Educação da UNESP - Rio Claro. Professora no IFSP - câmpus Salto.

E-mail: elianeab3@gmail.com. 